\title{
Luna, Pablo F. (2017) El tránsito de la Buenamuerte por Lima. Auge y declive de una orden religiosa azucarera siglos XVIII y XIX. Madrid, Biblioteca Indiana /Universidad de Navarra-Vervuert. 424 p.
}

\section{Emir Reitano}

Centro de Historia Argentina y Americana, Instituto de Investigaciones en Humanidades y Ciencias Sociales, Universidad Nacional de La Plata, Argentina ereitano@fahce.unlp.edu.ar

Cita sugerida: Reitano, E.(2018). [Reseña del libro El tránsito de la Buenamuerte por Lima. Auge y declive de una orden religiosa azucarera siglos XVIII y XIX de P. F. Luna]. Mundo Agrario, 19(42), e102. https://doi.org/10.24215/15155994e102

Recibido: 01 enero 2018- Aceptado: 17 octubre 2018 - Publicado: 07 diciembre 2018

(c) (1) (2) (2) Esta obra está bajo licencia Creative Commons Atribución-NoComercial-CompartirIgual 4.0 Internacional http://creativecommons.org/licenses/by-nc-sa/4.0/deed.es_AR 


\title{
Luna, Pablo F. (2017) El tránsito de la Buenamuerte por Lima. Auge y declive de una orden religiosa azucarera siglos XVIII y XIX. Madrid, Biblioteca Indiana / Universidad de Navarra-Vervuert. 424 p.
}

\author{
Emir Reitano \\ Universidad Nacional de La Plata, Argentina \\ ereitano@fahce.unlp.edu.ar
}

Hace más de 25 años Carlos Mayo señalaba que la inserción de la Iglesia en la sociedad y en la economía colonial configuraban uno de los temas más importantes de la historia latinoamericana, como así también el papel jugado por ella en la vida religiosa y cultural del Nuevo Mundo (Mayo, 1992). El libro de Pablo Luna viene a insertarse dentro de esta línea de investigación un cuarto de siglo después.

Fruto de labor de años de trabajo, que se vislumbran en la obra a través de un erudito estado de la cuestión, Pablo Luna exhibe un sólido conocimiento temático destacando virtudes y falencias dentro de este campo de estudio.

El autor logra a través de 5 capítulos, detallar la historia de la orden mendicante de San Camilo de Lelis en Lima, desde su llegada a Perú en 1709 hasta los últimos años del siglo XIX, sin dejar de lado todas las vicisitudes que le tocó vivir al mundo peruano desde la colonia hasta la guerra de independencia y la crisis del primer período independiente.

En un primer capítulo el autor desarrolla la actividad de la mencionada orden en el Perú Borbónico y los vínculos que la misma logró establecer. Se observan las prácticas del albaceazgo y la importancia que éste tuvo para el funcionamiento dinámico de la orden, las temporalidades urbanas, el manejo de las propiedades y la consolidación del prestigio de la orden dentro de la sociedad limeña. En ese sentido también se abordan los conflictos que los mendicantes de San Camilo tuvieron que afrontar, como las potestades del regio patronato entre otros.

En su segundo capítulo el libro nos introduce en la administración de las haciendas y la explotación de sus complejos azucareros. En este sendero la orden religiosa transita por los caminos esperados ya que la administración de un establecimiento azucarero durante el período colonial constituía una empresa que excedía la tarea de una hacienda. Un ingenio colonial necesitaba de una inmensa inversión de capital para la construcción de infraestructura para el funcionamiento de la maquinaria como también para su funcionamiento rural, la compra de esclavos, bestias de carga y herramientas de labranza. De ese modo los religiosos mendicantes de San Camilo de Lelis lograron consolidarse como una orden agrícola y azucarera en donde los avatares de la economía fueron dejando también su huella. Sin embargo sus administradores siempre estuvieron a la altura de las circunstancias actuando dentro del mercado con total desenvolvimiento. El azúcar se convirtió en un producto importante dentro de la economía peruana, abriendo nuevos mercados ante la crisis de algunas regiones productoras y activando otras áreas de la economía en el Perú colonial hasta la guerra de independencia que rompió con las estructuras de un sistema productivo en acción.

Sabemos los límites que impone un trabajo de esta envergadura, sin embargo es aquí donde el lector se queda con algunas preguntas no resueltas dentro del texto. No nos queda muy claro por qué los religiosos de la orden se volcaron a la producción y comercialización del azúcar en ese momento preciso, intuimos que la crisis del azúcar brasileño tuvo su impacto sumado a las divergentes imposiciones que la nueva casa real traía desde la península. Todos posibles factores. Tal vez la presentación de una perspectiva comparada con 
otras áreas azucareras no hubiera estado de más, ya que es vasta la producción historiográfica en ese sentido tanto para el área mesoamericana como también para el mundo luso brasileño. Los circuitos mercantiles y el mercado donde actuaba son aspectos que con un detenido análisis hubieran otorgado una mayor capacidad de respuesta ante tan inmenso trabajo de investigación en el que se combinan la erudición y el conocimiento que el autor posee.

El capítulo III destaca la importancia de los conflictos internos generados en el seno de la orden religiosa por dos grupos bien definidos y antagónicos. En ellos la crisis institucional no se hizo esperar. Como suele suceder, los conflictos ponen en evidencia a una sociedad colonial activa en donde la ausencia de los mismos, al no dejar vestigios, siempre juega en contra para el taller del historiador. Gracias a estos conflictos las fuentes son abundantes y aunque las mismas estén cargadas de subjetividad, el autor logra con suma prudencia y profesionalidad obtener un resultado adecuado y equilibrado en su análisis. Esta evocación del conflicto ha permitido recrear aspectos reveladores sobre la composición de la orden, su vida cotidiana y su forma de actuar ante la sociedad limeña, su relación con el poder borbónico y su administración del capital con sus respectivos envíos a Europa.

El capítulo IV se aboca al estudio de la "desamortización eclesiástica" de la Buenamuerte y la crisis que acarreó el esperado declive, llegando con él la supresión de la orden con la posterior utilización de sus propiedades y finanzas. Todo ello relacionado con el contexto de la guerra, la independencia y los conflictos que la misma fue acarreando tanto para la orden como también para la sociedad peruana en general. Por este motivo los capítulos finales se enmarcan en el análisis de la crisis política del Perú postcolonial, donde las discusiones en torno al patrimonio improductivo de la iglesia dentro del discurso liberal, como también la concepción teórica de la desamortización eclesiástica, tuvieron un plano fundamental en la sociedad. El libro en ese aspecto pone en evidencia con total claridad esa compleja trama en donde el patrimonio y las finanzas de la orden transitaron por los complicados senderos del proceso revolucionario. La última parte del libro se vincula claramente a la crisis en la cual, el estado independiente encontrará en el clero secular un aliado y donde las órdenes religiosas ya no tendrán espacio donde ubicarse. En ese camino la orden perderá sus propiedades rurales, acreedores y enfitueutas tendrán cuota de lo suyo y por ello obligarán a los religiosos a su repliegue urbano hacia mediados del siglo.

Cabe destacar que el libro está atravesado por un minucioso trabajo de investigación en donde abundan los estudios de caso y la prosopografía que se continúan a lo largo de todo el texto.

Pablo Luna es conciente de los límites que debe tener su obra. Ya en la introducción de la misma el autor señala que la propiedad y el patrimonio eclesiásticos en el Perú desde el Antiguo Régimen hasta la sociedad contemporánea, forman parte de un capítulo de la historia peruana que no han sido examinados con el detenimiento y la precisión necesarios. Sin embargo el libro viene a ocupar un espacio tan importante como necesario en ese sendero que queda por transitar, donde se hace necesario un abordaje con más estudios de casos. El camino está marcado... solo hace falta ponerse en marcha.

\section{Referencias}

Mayo, C. A. (1992). Los Betlemitas en Buenos Aries: convento, economía y sociedad (1748-1822), Sevilla: Junta de Andalucía. 